\title{
Fear of blushing: effects of task concentration training versus exposure in vivo on fear and physiology.
}

Citation for published version (APA):

Mulkens, S., Bögels, S. M., de Jong, P. J., \& Louwers, J. (2001). Fear of blushing: effects of task concentration training versus exposure in vivo on fear and physiology. Journal of Anxiety Disorders, 15, 413-432. https://doi.org/10.1016/S0887-6185(01)00073-1

Document status and date:

Published: 01/01/2001

DOI:

10.1016/S0887-6185(01)00073-1

Document Version:

Publisher's PDF, also known as Version of record

Document license:

Taverne

Please check the document version of this publication:

- A submitted manuscript is the version of the article upon submission and before peer-review. There can be important differences between the submitted version and the official published version of record.

People interested in the research are advised to contact the author for the final version of the publication, or visit the DOI to the publisher's website.

- The final author version and the galley proof are versions of the publication after peer review.

- The final published version features the final layout of the paper including the volume, issue and page numbers.

Link to publication

\footnotetext{
General rights rights.

- You may freely distribute the URL identifying the publication in the public portal. please follow below link for the End User Agreement:

www.umlib.nl/taverne-license

Take down policy

If you believe that this document breaches copyright please contact us at:

repository@maastrichtuniversity.nl

providing details and we will investigate your claim.
}

Copyright and moral rights for the publications made accessible in the public portal are retained by the authors and/or other copyright owners and it is a condition of accessing publications that users recognise and abide by the legal requirements associated with these

- Users may download and print one copy of any publication from the public portal for the purpose of private study or research.

- You may not further distribute the material or use it for any profit-making activity or commercial gain

If the publication is distributed under the terms of Article $25 \mathrm{fa}$ of the Dutch Copyright Act, indicated by the "Taverne" license above, 


\title{
Fear of blushing: Effects of task concentration training versus exposure in vivo on fear and physiology
}

\author{
Sandra Mulkens ${ }^{\mathrm{a}, *}$, Susan M. Bögels ${ }^{\mathrm{b}}$, Peter J. de Jong ${ }^{\mathrm{b}}$, \\ Judith Louwers ${ }^{\mathrm{b}}$ \\ ${ }^{a}$ Department of Experimental Psychology, Faculty of Psychology, Maastricht University, \\ Maastricht, The Netherlands \\ ${ }^{\mathrm{b}}$ Department of Medical, Clinical and Experimental Psychology, Faculty of Health Sciences, \\ Maastricht University, Maastricht, The Netherlands
}

Received 1 September 1998; received in revised form 10 July 2000; accepted 8 May 2001

\begin{abstract}
Patients with fear of blushing as the predominant complaint $(N=31)$ were randomly assigned to (1) exposure in vivo (EXP), or (2) task concentration training (TCT), in order to test the effect of redirecting attention above exposure only. In addition, it was investigated whether treatment reduced actual blush behavior; therefore, physiological parameters of blushing were measured during two behavioral tests. Half of the patients served as waiting-list controls first. Assessments were held before and after treatment, at 6weeks, and at 1-year follow-up. Both treatments appeared to be effective in reducing fear of blushing and realizing cognitive change. Yet, at posttest, TCT tended to produce better results with respect to fear of blushing. At 6-weeks follow-up, TCT produced significantly more cognitive change. At 1-year follow-up, patients further improved, while differential effects had disappeared. The reduction in fear of blushing was not paralleled by a reduction in actual blush behavior during the behavioral assessments. Thus, it seems that fear of blushing reflects a fearful preoccupation, irrespective of actual facial coloration. (C) 2001 Elsevier Science Inc. All rights reserved.
\end{abstract}

* Corresponding author. Department of Experimental Psychology, Faculty of Psychology, Maastricht University, Maastricht, The Netherlands.

E-mail address: s.mulkens@psychology.unimaas.nl (S. Mulkens). 
Keywords: Blushing; Fear of blushing; Social phobia; Behavioral treatment; Physiology; Cheek coloration

\section{Introduction}

Individuals with social phobia almost always experience symptoms of anxiety in social situations (e.g., blushing, palpitations, tremors, sweating, etc.) (American Psychiatric Association, 1994). In various cases, anxiety seems to be centered around the showing of physical symptoms (like blushing), turning the occurrence of these bodily reactions into the source of fear; in many social phobics, fear of blushing appears to be a prominent complaint, indeed (Edelmann, 1990).

In the last 15 years, several controlled treatment outcome studies have been conducted on social phobia, including individual as well as group treatment, and comparisons between purely behavioral, purely cognitive, and combined cognitive-behavioral treatment methods (e.g., Butler, Cullington, Munby, Amies, \& Gelder, 1984; Emmelkamp, Mersch, Vissia, \& Van der Helm, 1985; Gelernter et al., 1991; Heimberg et al., 1990; Hope, Heimberg, \& Bruch, 1995; Mattick \& Peters, 1988; Mattick, Peters, \& Clarke, 1989; Scholing \& Emmelkamp, 1993b). The results of these studies generally show that, although social phobia has been linked to cognitive distortions, behavioral and cognitive treatments are equally effective (Feske \& Chambless, 1995).

Yet, it remains largely unclear whether results of these studies can also be applied to social phobia with fear of blushing as the predominant complaint. Thus far, only two controlled treatment outcome studies have investigated the effects of cognitive-behavioral treatments for social phobics with fear of bodily symptoms as the central complaint. One study compared exposure followed by cognitive therapy, cognitive therapy followed by exposure, and a package in which both methods were integrated from the start (Scholing \& Emmelkamp, 1993a), whereas the other study compared cognitive therapy to applied social skills training (Bögels, 1994). All treatment methods that were used in these studies proved equally effective. However, in both studies, effect sizes were rather modest, supporting the clinical impression that social phobics with fear of bodily symptoms are relatively difficult to treat.

One way to enhance treatment efficacy in blushing phobics may be to specifically address detrimental attentional processes. That is, social phobics tend to focus attention excessively on themselves in social situations ['heightened self-focused attention (SFA)'] (e.g., Clark \& Wells, 1995; Daly, Vangelisti, \& Lawrence, 1989; Hope, Gansler, \& Heimberg, 1989; Wells \& Matthews, 1994). As a result, feelings of anxiety, (awareness of) physical symptoms, and awareness of negative ideas about the self might be caused. Furthermore, less 
attention might be available to be directed at the task at hand, which is likely to result in poor social performance (Bögels, Mulkens, \& de Jong, 1997; Clark \& Wells, 1995).

It is important to note that the experience of social attention might be especially detrimental to people with fear of blushing. It is known that undesired social attention and concern over appearance are elicitors of blushing (cf. Leary, Britt, Cutlip, \& Templeton, 1992), whereas the experience of blushing is likely to intensify public self-consciousness (e.g., Wegner \& Giuliano, 1980). Thus, blushing phobics seem to be captured in a vicious circle. Given the possibly detrimental effects of enhanced SFA, teaching blushing phobics to focus attention on the pertinent aspects of the situation (the 'task'), instead of focusing inward on feelings, thoughts, and symptoms, might well be helpful in treating anxiety (Bögels et al., 1997).

Therefore, we developed an attention training for fear of blushing, task concentration training (TCT). TCT consists of three phases: (1) getting insight into attentional processes and the effects of focusing attention on the self, (2) focusing attention outward in nonthreatening situations, and (3) focusing attention outward in threatening situations. Thus, attention training aims to make patients aware of what is really going on around them and, as a consequence, to reevaluate their thoughts about the feared situations. Moreover, as SFA appears incompatible with task focus, attending to the (social) task may be considered as an active coping technique. Several exploratory case studies (Bögels et al., 1997; Mulkens, Bögels, \& de Jong, 1999) have revealed promising results.

The aim of the present study was to investigate the effectiveness of TCT compared to exposure in vivo (EXP): an existing treatment of which the effects on social phobia are well-established (e.g., Taylor, 1996). Another reason for choosing EXP as a comparison treatment is the shared component in both treatments of the hierarchical practicing of social situations. Therefore, such a comparison allows us to evaluate whether adding attention training enhances the efficacy of exposure only.

We investigated the effects of TCT and EXP on self-report measures of erythrophobia, as well as on actual blushing behavior. Furthermore, TCT was expected to specifically influence blushing phobics' negative cognitions, by providing the opportunity to experience disconfirming information (cf. Bögels et al., 1997; Clark \& Wells, 1995). To investigate the relative efficacy of TCT, erythrophobics were treated individually with either EXP or TCT. Half of the subjects served as a waiting-list control group, waiting 6 weeks before receiving treatment. Before and after treatment (or waiting list), we assessed patients' fear of blushing and negative cognitions, and carried out a behavioral test, during which actual blushing (i.e., blood pooling in the cheek) and self-reported blushing intensity were recorded. Inclusion of both objective (i.e., physiology) and subjective indices of blushing allows to differentiate between fearful preoccupation and actual 
facial coloration (cf. Mulkens, de Jong, \& Bögels, 1997; Mulkens, de Jong, Dobbelaar, \& Bögels, 1999).

\section{Method}

\subsection{Patients}

Patients were included in the study when they met the following criteria: a primary diagnosis of social phobia (DSM-IV), with fear of blushing in social situations as the prominent fear, no (cognitive-) behavioral treatment for erythrophobia in the past 2 years, no use of medication for fear of blushing. Patients were recruited by means of advertisements, in which people who suffered from fear of blushing were offered treatment.

Patients were first screened over the telephone, after which 40 individuals were invited for an intake session. They were interviewed by means of a structured clinical interview for DSM-III-R disorders (the SCID; Spitzer \& Williams, 1986). Furthermore, they were asked to fill out the subscale 'fear of blushing' of the Blushing, Trembling, and Sweating Questionnaire (BTS-Q; Bögels \& Reith, 1999) on which they had to score above a certain cut-off point: at least 1.5 S.D.s higher than the mean score obtained by students (Bögels, Alberts, \& de Jong, 1996), implying that men had to score at least 38.6 and women 51.2 (range $0-100$ ).

Nine of the 40 individuals undergoing the intake did not enter treatment: four appeared to be not rightly classified, four did not accept treatment because of practical reasons, and one did not show up anymore. All remaining 31 patients (seven men) had a primary diagnosis of social phobia, with fear of blushing as the predominant complaint. At intake, mean 'fear of blushing' scores were 65.7 (S.D. 12.8) and 77.0 (S.D. 14.5) for women and men, respectively.

\subsection{Experimental design and procedure}

All patients were screened by the first author, and SCID interviews were conducted by a trained psychologist. After the intake session, the first assessment took place (Pretest I), after which half of the patients started immediately with the treatment, being randomly assigned to EXP or TCT. The other half started treatment after a 6-week waiting-list period, at the end of which a second assessment took place (Pretest II). Then, these latter patients were also randomly assigned to one of the two treatments. Of the 31 patients who started treatment, 5 patients dropped out (16\%): 3 from TCT, 2 from EXP. Eventually, 12 patients finished the EXP treatment, and 14 finished the TCT treatment. Patients were assessed on behavioral tests, on questionnaires, and on diary recordings at Pretest I, Pretest II, and Posttest. After a 6-week follow-up period (FU I), and after 1 year (FU II), they completed the questionnaires again. 


\subsection{Treatment}

\subsubsection{Therapists}

Five female students, who had almost finished their studies in Mental Health Sciences at Maastricht University and had passed a clinical training, functioned as therapists. They received an intensive 3-day training in the treatment procedures, provided by the first and second authors. All therapists attended weekly supervision sessions.

\subsubsection{General aspects}

Both treatments consisted of six weekly 1-h sessions. Both treatments followed an identical structure: in Session 1 the rationale was explained, in Session 2 general exercises were done, in Session 3 a hierarchy of fearful situations was constructed, and in the following three sessions the items from the hierarchy were practiced within and between sessions, by means of role plays and in vivo exercises. Both rationales emphasized that the aim of treatment was to become less afraid of blushing, and not to eliminate blushing. Patients were instructed to practice extensively between sessions (at least 5 out of 7 days), using homework diaries. Both treatments were kept pure; that is, no skills training or cognitive restructuring took place.

\subsubsection{Exposure in vivo}

The EXP treatment was based on the latest insights into active exposure components, that is, refraining from subtle avoidance strategies (like averting the eyes or the body when blushing, wearing make-up) and dropping safety behaviors (Wells et al., 1995). It was explained that by prolonged, graded, and frequent exposure to feared situations, without applying (subtle) avoidance strategies, the fear of blushing would eventually diminish. Standardized unusual exposure exercises were done in Session 2, built up hierarchically: from sitting silently for $2 \mathrm{~min}$ without having eye contact (sitting back-toback), to eventually sitting face-to-face, having eye contact without saying anything for $2 \mathrm{~min}$. Patients rated their anxiety (range $=0-100$ ) before and at the end, and their highest fear during the exercise. These exercises were repeated, until fear decreased substantially. Homework assignments between Sessions 2 and 3-4 were to make diary registrations of situations in which patients had fear of blushing (i.e., kind of situation, whether they had encountered or avoided it, whether they blushed, how they felt and with which intensity, and what the consequence of avoidance had been), and to do unusual things that had nothing to do with fear of blushing, like wearing two different socks, or reading a 'wrong' magazine in the presence of other people. This was to demonstrate that behaving differently causes tension, but habituates. In the third session, an individual fear hierarchy was constructed, which was practiced between and within sessions throughout the remaining treatment. 


\subsubsection{Task concentration training}

In the rationale of TCT, the role of SFA in the maintenance of fear of blushing was emphasized. The effects of SFA were demonstrated by an exercise: patients were asked to tell the therapist a short story about their latest holidays, thereby focusing all attention on the self: on thoughts, feelings, the way they thought they came across to the therapist, etc. Then, the detrimental effects of SFA were discussed, and connected to their daily social difficulties (Bögels et al., 1997). The aim of the treatment would be to learn to direct more attention to the task at hand instead of focusing on the self, so that the vicious circle of SFA and fear of blushing would be broken and fear of blushing would decrease. In the second session, concentration exercises were done in order to demonstrate the beneficial effects of task-focused attention. These were listening exercises, built up hierarchically (see Bögels et al., 1997 for details). Homework assignments between Sessions 2 and 3-4 were to make diary registrations of the direction of attention in blushing-fearful situations, and to do general, nonthreatening concentration exercises. For example, walking through a quiet forest and focusing attention alternately on the different sensorial aspects of the environment, watching the news very concentratedly and summarizing it afterwards, etc. In the third session, an individual fear hierarchy was constructed, which was practiced between and within sessions throughout the remaining treatment. The aim was to practice directing attention to the task in these situations.

\subsection{Assessment}

\subsubsection{Questionnaires}

The following questionnaires were completed:

2.4.1.1. The Social Phobia and Anxiety Inventory (SPAI; Turner, Beidel, Dancu, \& Stanley, 1989; Dutch translation: Scholing, Bögels, \& van Velzen, 1995). The social phobia subscale, which measures aspects of generalized social phobia, was used for descriptive purposes. Patients rated each item on a seven-point scale, rescaled from 0 (never) to 6 (always) (range 0-192). The internal consistency is very high (.99; Bögels \& Reith, 1999).

\subsubsection{The Blushing Propensity Scale (BPS; Leary \& Meadows, 1991; Dutch} version: Bögels et al., 1996). The Dutch BPS consists of 19 circumscribed social situations for each of which the subject has to indicate how often she feels herself blushing. Answers range from 0 (I never feel myself blushing in that situation) to 4 (I always feel myself blushing in that situation). The internal consistency of the Dutch BPS is high (.92; Bögels et al., 1996), as is its testretest reliability (.93; Mulkens et al., 1997).

2.4.1.3. The Blushing, Trembling, and Sweating Questionnaire (BTS-Q; Bögels \& Reith, 1999). In this study, we only used the part concerning blushing. The 
subscale 'fear of blushing' measures, by visual analog scales (VASs), to what degree patients are afraid to blush and experience blushing as a problem (range $=0-100$ ). The subscale 'bodily reactions while blushing' indicates to what extent certain bodily reactions are experienced during blushing (range $=0-4)$. The subscale 'blushing consequences' indicates to what extent the patient, when blushing, is hindered by disturbances in mental processes, such as blackouts or problems in concentrating (range $=0-4$ ). The subscale 'blushing cognitions' consists of positive and negative cognitions about blushing and its social consequences, which are given a proportional score of $0 \%$ (' $\mathrm{I}$ do not believe it at all') to $100 \%$ ('I'm totally convinced') (range $=0-100$ ). The subscale 'avoidance of blushing' measures the extent to which strategies are used to avoid or hide blushing (range $=0-4$ ). The last subscale of the BTS-Q asks the patient to estimate how many times he or she blushed in the past week. The homogeneity of the BTS$\mathrm{Q}$ is satisfactory for all subscales (ranging from 0.77 to 0.98 ). Furthermore, the BTS-Q has good discriminant validity; it is able to discriminate not only social phobics from controls, but also social phobics with fear of bodily symptoms like blushing from social phobics without such fears (Bögels \& Reith, 1999).

2.4.1.4. The SFA scale (Bögels et al., 1996). This is a newly developed scale to measure the focus of self-attention. It consists of 11 items: 6 items refer to selfattention focused on one's arousal (SFA-arousal) (range $=0-24$ ), and 5 items concern self-attention directed to one's interpersonal behavior (SFA-performance) (range $=0-20)$. The internal consistency is high for both subscales $(.86$ and .78, respectively; Bögels et al., 1996).

\subsubsection{Idiosyncratic dysfunctional beliefs}

Four main idiosyncratic dysfunctional beliefs (causal catastrophic misinterpretations, CCMs) of each patient with regard to their blushing were assessed during the intake. An example of a CCM is: 'When I blush, I look stupid'. Before and after each treatment session, patients rated the beliefs on VASs (range 0-100).

\subsubsection{Diary measures}

Patients were instructed to record their blushing, anxiety, and associated behavior systematically on self-monitoring diaries in the week prior to the start of the treatment or waiting period and in the last week of the treatment or waiting period. Everyday, patients answered questions concerning the extent to which they had had fear of blushing (range 0-4), the intensity of this fear [ranging from 0 (not at all) to 100 (very much)], the extent to which they had conducted (subtle) avoidance behavior and safety strategies (range $0-4$ ), and which strategies they used to become less anxious (0-4).

\subsubsection{Behavioral and physiological assessment}

The behavioral assessment consisted of a conversation with two stooges (interaction test), and a short speech before an audience of four people 
(performance test), taken in a fixed order, during which physiological responses were recorded. To measure changes in blood flow in the cheek, a photoplethysmograph probe was attached to the left cheek and a temperature probe to the right cheek of the subject. Skin conductance electrodes were placed on the medial phalanges of the middle finger and ring finger of subjects' nondominant hand. Cheek coloration was recorded from an HP model 15230A plethysmograph transducer that was modified in such a way that it was DC-coupled rather than AC-coupled. The probe operates in the infrared spectrum. Cheek temperature was assessed by means of a temperature-dependent resistor (PT100) that was DC-coupled. Skin conductance level was recorded from two Beckman $\mathrm{Ag}-\mathrm{AgCl}$ electrodes ( $8 \mathrm{~mm}$ diameter), placed on the medial phalanges of the middle finger and ring finger of the subject's nondominant hand, using the method of constant voltage $(0.5 \mathrm{~V})$. The electrodes were filled with an isotonic paste and connected to a Beckman Skin Conductance Coupler (type 9844). All physiological signals were sampled with a frequency of $1000 \mathrm{~Hz}$ by a Compaq $486(33 \mathrm{MHz})$ computer.

When all equipment had been attached, the research assistant left the room and asked the patient to sit and relax for a short while $(2.5 \mathrm{~min})$, during which a baseline recording was made. After that, the patient filled out a short self-report, consisting of two VASs ('How anxious were you in the past 2.5 minutes?' and 'How much did you blush during the past 2.5 minutes?').

Then, patients were informed that they were expected to have a conversation with two people (a man and a woman) during $5 \mathrm{~min}$ (cf. Öst, Jerremalm, \& Johansson, 1981) and that these two stooges would make notes to judge their interaction behavior. After the conversation, patients filled out the self-report again. Physiological responses were recorded during another period of $2.5 \mathrm{~min}$, in order to measure physiological recovery from the conversation.

After a 20-min break (recovery period), patients did the second test. After a 2.5-min baseline measurement and the completion of the two self-report VASs, the test was explained. The patient was told to give a 3-min speech in front of an audience of four people, after 2 min preparation time. The subject of the speech could be freely chosen. The audience would judge the patient's skills. After the test, the patient completed the self-report, whereas the physiology was recorded for an additional $2.5 \mathrm{~min}$ (recovery).

\subsection{Treatment credibility and integrity}

Treatment credibility was firstly assessed after the rationale was explained. Patients filled out a three-item questionnaire: (1) how logical does this form of treatment seem to be for you?; (2) how confident are you that this treatment will help you overcome your fear of blushing?; and (3) to what extent would you advise this treatment to a friend with similar problems? On a scale, from 1 (not at all ) to 9 (extremely). Treatment credibility was again assessed at posttest, at FU I, and at FU II. 
Treatment integrity was assessed by audiotaping all treatment sessions. The first author listened to 10-min segments of tapes chosen at random and compared the content to the treatment manual. Feedback about the audiotaped sessions was given during supervision, in order to maximize the purity of the treatments. To determine whether the training had led to the predicted strategic behavior, patients indicated in diaries (see diary measures) what strategies they used to become less anxious: relaxation, thinking less catastrophically, concentrating on the task at hand (i.e., TCT), or staying in the situation until the anxiety diminished (i.e., EXP).

\subsection{Data reduction}

In this study, two broad questions were addressed, each divided into more specific questions: (1) what is the effect of treatment vs. waiting list on (a) fear of blushing and cognitive change, and (b) actual blushing and self-reported blushing and anxiety during behavioral tests; and (2) are there differential treatment effects of TCT vs. EXP on (a) fear of blushing and cognitive change, and (b) actual blushing and self-reported blushing and anxiety during behavioral tests? Both (a) questions will be addressed by using the self-report questionnaires and the CCMs, whereas physiological variables and self-reports of the behavioral tests will serve to address the (b) questions.

To minimalize the risk of Type I errors, dependent variables were divided into two groups: outcome and descriptive variables. Only the first set of variables was used to test the hypotheses. To measure changes in 'fear of blushing', we used two outcome variables: the BTS-Q subscale 'fear of blushing' and a newly composed measure, built up from the Blushing Propensity Scale (BPS) and the BTS-Q subscales 'bodily reactions while blushing', 'blushing consequences', and 'avoidance of blushing'. This composite variable is called 'blushing responsiveness and consequences'. To measure cognitive change, the BTS-Q subscale 'negative cognitions' and the CCMs were used. To this end, mean CCM scores at the start and at the end of waiting and treatment, respectively, were computed. The other variables (diaries, ${ }^{1}$ SPAI, SFA-arousal, SFA-performance, BTS-Qblushing frequency, and BTS-Q-positive cognitions) were used for descriptive purposes only.

With regard to the (b) questions (effects on actual blushing), we used the cheek coloration data from the behavioral tests. These data were analyzed as follows: every $30 \mathrm{~s}$ the level was selected, resulting in 10 values during the conversation, and 6 values during the presentation. Mean values were calculated for each period. We also collected cheek temperature and skin conductance data.

${ }^{1}$ The descriptive diary data were reduced by calculating a composite measure, constructed of two correlated ( $r=0.50, P=.005)$ variables: 'Fear of blushing' (the item 'the extent of fear of blushing' multiplied by 'the intensity of this fear', resulting in a range of $0-400$ ) and 'avoidance' (built up out of diary items that all measured aspects of avoidance (range 0-4)). 
However, the results obtained were highly similar and thus only the results for the cheek coloration data are presented, whereas the results of cheek temperature and skin conductance level are presented in a footnote.

To investigate changes in self-reported blushing and anxiety, self-report data during the behavioral tests were used. Because these data violated the assumption of normality, transformations were performed, using the following formula: $\operatorname{nvar}=\ln ((\operatorname{var}+1) /(101-$ var $))$.

\subsection{Statistical analyses}

Of the 31 subjects who originally started treatment, 4 (in the 'treatment-atonce' condition) were eliminated from the final data analysis due to a failure to complete treatment. One subject (in the 'waiting-list' condition) completed most of the waiting-list measurements (that is, CCMs were available, and the data of the behavioral assessment) but dropped out during treatment. This case was included in the analyses of the 'waiting-list' vs. 'treatment-at-once' effects. Two patients (both waiting-list controls) refused to do one or more behavioral tests because they felt too anxious to carry them out. At FU II, 21 patients returned their questionnaires: 9 in the EXP condition, and 12 in the TCT condition. Only patients who completed both posttest and FU II assessments, were included in the comparison analyses of pretest vs. 1-year follow-up, and posttest vs. 1-year follow-up.

Waiting-list effects vs. treatment effects and differential treatment effects were tested with multivariate analyses of variance (MANOVAs) with one betweengroups factor (Group: waiting vs. treatment, or Condition: EXP vs. TCT), using difference scores between relevant time assessments.

To determine clinically significant change, the number of patients who improved significantly in both treatments were compared by means of a chisquare. When norms of a functional population are available, Jacobson and Truax (1991) advise using the point that lies halfway between the mean of the functional and dysfunctional population. Cutoff scores of 45.7 and 43.5 were established for men and women, respectively [using the means of the present dysfunctional population, and a functional population from Bögels \& Reith, 1999 (i.e., 14.5 for men, and 21.3 for women)]. Effect sizes of changes in fear of blushing were computed as an indication of treatment effects (Cohen, 1988).

\section{Results}

\subsection{Dropouts versus completers}

Five patients dropped out during treatment, because of lack of confidence in the treatment, time constraints, improvement, fear, or a combination of these 
reasons. A striking demographic feature was the difference between dropouts and completers in the mean duration of their complaint, being only 4.6 (S.D. 3.1) years for dropouts, and 13.5 (S.D. 10.1) years for completers. Shorter duration might imply less distress and, therefore, sooner dropping out. Still, dropouts had higher initial 'fear of blushing' scores (75.1; S.D. 15.6) than completers (62.1; S.D. 16.3).

\subsection{Waiting list versus treatment at once}

Results regarding outcome are summarized in Tables 1 and 2.

\subsection{1. (1a) Effects on fear of blushing}

The MANOVA revealed a significant effect of treatment above waiting list, $[F \operatorname{hot}(2,23)=4.5, P<.05]$. Univariate $F$ tests showed that this effect was mainly due to the variable 'blushing responsiveness and consequences' $[F(1,24)=9.4, P=.005]$, and to a lesser extent to the variable BTS$\mathrm{Q}$ 'fear of blushing' $[F(1,24)=3.7, P=.07]$. Thus, it can be concluded that a 6-week treatment produces better results than waiting list (see also Table 1).

\subsection{2. (1a) Effects on negative cognitions}

The MANOVA yielded no significant effect of treatment above waiting list $[F \operatorname{hot}(2,23)=1.7]$. However, there was an overall significant decrease in negative cognitions $[F \operatorname{hot}(2,24)=11.5, P<.001]$ (see also Table 1 ).

Table 1

Effects of waiting (WL) versus treatment (NWL) on outcome measures (mean and S.D.)

\begin{tabular}{lcc}
\hline Variable & Pretest I & Pretest II/ Posttest \\
\hline BTS- $Q-$ fear of blushing & $63.11(19.18)$ & \\
WL $(n=14)$ & $60.74(12.78)$ & $56.44(20.18)$ \\
NWL $(n=12)$ & & \\
& & \\
Blushing responsiveness and consequences & $2.64(20.28)$ \\
WL $(n=14)$ & $2.24(0.41)$ & $2.22(0.40)$ \\
NWL $(n=12)$ & $1.96(0.42)$ & $1.56(0.55)$ \\
& & \\
BTS- $Q-N e g a t i v e ~ c o g n i t i o n s$ & $58.00(9.81)$ & $50.87(9.98)$ \\
WL $(n=14)$ & $48.63(20.47)$ & $35.21(21.69)$ \\
NWL $(n=12)$ & & \\
$C C M s$ & $83.55(9.75)$ & $73.07(12.86)$ \\
WL $(n=15)$ & $75.08(13.40)$ & $49.25(25.07)$ \\
NWL $(n=12)$ &
\end{tabular}


Table 2

Effects of waiting (WL) versus treatment (NWL) on three physiological measures, self-reports of blushing, and self-reports of anxiety during conversation, and presentation (mean and S.D.)

\begin{tabular}{|c|c|c|c|}
\hline Variables & & Pretest I & Pretest II/Posttest \\
\hline \multicolumn{4}{|l|}{ Conversation } \\
\hline \multirow[t]{2}{*}{ Cheek coloration $(\mathrm{V})$} & $\mathrm{WL}(n=14)$ & $4.25(2.29)$ & $3.32(1.98)$ \\
\hline & NWL $(n=9)$ & $3.06(1.75)$ & $1.22(2.80)$ \\
\hline \multirow[t]{2}{*}{ Cheek temperature $\left({ }^{\circ} \mathrm{C}\right)$} & WL $(n=14)$ & $3.23(0.20)$ & $3.20(0.14)$ \\
\hline & NWL $(n=9)$ & $3.14(0.15)$ & $3.18(0.19)$ \\
\hline \multirow[t]{2}{*}{$\mathrm{SCL}^{\mathrm{a}}(\mu \mathrm{mho})$} & WL $(n=12)$ & $1.88(0.26)$ & $1.64(0.67)$ \\
\hline & NWL $(n=10)$ & $1.58(0.47)$ & $1.72(0.66)$ \\
\hline \multirow[t]{2}{*}{ Self-reported blushing (transformed) ${ }^{\mathrm{b}}$} & WL $(n=14)$ & $0.42(1.19)$ & $-0.64(1.58)$ \\
\hline & NWL $(n=12)$ & $-1.05(1.93)$ & $-2.23(1.62)$ \\
\hline \multirow[t]{2}{*}{ Self-reported anxiety (transformed) ${ }^{b}$} & WL $(n=14)$ & $0.45(1.67)$ & $-0.57(1.94)$ \\
\hline & NWL $(n=12)$ & $-0.33(1.32)$ & $-1.48(1.61)$ \\
\hline \multicolumn{4}{|l|}{ Presentation } \\
\hline \multirow[t]{2}{*}{ Cheek coloration (V) } & $\mathrm{WL}(n=14)$ & $3.10(2.46)$ & $2.70(1.70)$ \\
\hline & NWL $(n=9)$ & $2.87(2.26)$ & $2.00(1.68)$ \\
\hline \multirow[t]{2}{*}{ Cheek temperature $\left({ }^{\circ} \mathrm{C}\right)$} & WL $(n=14)$ & $3.24(0.18)$ & $3.24(0.17)$ \\
\hline & NWL $(n=9)$ & $3.21(0.19)$ & $3.21(0.19)$ \\
\hline \multirow[t]{2}{*}{$\mathrm{SCL}^{\mathrm{a}}(\mu \mathrm{mho})$} & WL $(n=12)$ & $1.77(0.29)$ & $1.60(0.73)$ \\
\hline & NWL $(n=10)$ & $1.54(0.32)$ & $1.56(0.61)$ \\
\hline \multirow[t]{2}{*}{ Self-reported blushing (transformed) ${ }^{\mathrm{b}}$} & WL $(n=14)$ & $-0.47(1.62)$ & $-0.92(1.57)$ \\
\hline & NWL $(n=12)$ & $-0.59(2.12)$ & $-1.37(1.94)$ \\
\hline \multirow[t]{2}{*}{ Self-reported anxiety (transformed) ${ }^{b}$} & WL $(n=14)$ & $0.68(1.31)$ & $-0.27(1.66)$ \\
\hline & NWL $(n=12)$ & $0.36(0.84)$ & $-0.48(1.20)$ \\
\hline
\end{tabular}

${ }^{a}$ SCL values are SQRT transformed.

b Self-reports are transformed using this formula: nvar $=\ln ((\operatorname{var}+1) /(101-$ var $))$.

\subsection{3. (1b) Effects on actual blushing}

Plethysmograph values at different occasions are summarized in Table 2. The MANOVA revealed no significant difference between treatment and waiting $[F \operatorname{hot}(2,20)=0.23] .^{2}$ Furthermore, there was no significant overall decrease in actual blushing $[F \operatorname{hot}(2,21)=1.8, P>.1]$.

\subsection{4. (1b) Effects on self-reported blushing and anxiety}

In Table 2, values of self-reported blushing and anxiety on different occasions are presented. The MANOVA with regard to self-reported blushing did not reveal a difference between treated patients and waiting-list patients $[F \operatorname{hot}(2,23)=0.15]$, nor did the MANOVA with regard to self-reported anxiety $[F \operatorname{hot}(2,23)=0.07]$. Yet, for both variables, there appeared to be an overall significant decrease at the second behavioral test $[F \operatorname{hot}(2,25)=11.1, P<.001$ and $F \operatorname{hot}(2,25)=15.9$, $P<.001$, respectively].

${ }^{2}$ The MANOVAs with regard to cheek temperature and skin conductance level revealed no significant main effect of group $[F(2,20)=0.77$, and $F(2,19)=1.87, P=.18$, respectively]. 


\subsection{Differential treatment effects}

Results on outcome and descriptive variables are summarized in Tables 3, 4 , and 5 .

\subsubsection{Credibility of treatment rationale and treatment integrity}

There was no difference between the two treatments concerning credibility of the treatment rationale on any given moment: pretest $[t(24)=-0.5$ (means being 6.43 (S.D. 1.29) for EXP and 6.64 (S.D. 0.95) for TCT], posttest $[t(24)=-0.3$ (means 6.42 (S.D. 1.38) and 6.64 (S.D. 1.95) for EXP and TCT, respectively], FU I $[t(24)=0.4$ (means 6.64 (S.D. 1.43) and 6.38 (S.D. 1.90) for EXP and TCT, respectively], and FU II $[t(19)=0.5$ (means 6.30 (S.D. 1.58) and 6.25 (S.D. 2.26) for EXP and TCT, respectively].

Inspection of the patients' diaries revealed that EXP patients indicated that they did not practice any of the strategies more frequently after treatment. Patients in the TCT group, however, practiced 'concentrating on the task at hand' significantly more often after treatment $[t(13)=4.2, P<.001$ (means being 1.3 and 2.4 before and after treatment, respectively], whereas there were no differences with respect to the other strategies.

\subsection{2. (2a) Effects on fear of blushing}

There was a borderline significant treatment effect of TCT above EXP at posttest $[F \operatorname{hot}(2,23)=3.2, P=.06]$. At FU I, this effect had disappeared $[F \operatorname{hot}(2,23)=0.2]$. When pretest was compared to FU II, no differential effects were present either $[F \operatorname{hot}(2,18)=0.2]$. A comparison of posttest with

Table 3

Effects of EXP versus TCT on outcome measures (mean and S.D.) on four test occasions

\begin{tabular}{|c|c|c|c|c|}
\hline Variable & Pretest & Posttest & FU I & $\mathrm{FU} \mathrm{II}^{\mathrm{a}}$ \\
\hline \multicolumn{5}{|c|}{$B T S-Q$ - fear of blushing } \\
\hline $\operatorname{EXP}(n=12)$ & $51.26(16.49)$ & $42.82(20.72)$ & $30.60(18.73)$ & $28.17(19.49)$ \\
\hline TCT $(n=14)$ & $64.56(15.37)$ & $45.79(21.20)$ & $40.18(20.50)$ & $34.17(24.48)$ \\
\hline \multicolumn{5}{|c|}{ Blushing responsiveness and consequences } \\
\hline $\operatorname{EXP}(n=12)$ & $2.16(0.39)$ & $1.74(0.57)$ & $1.71(0.63)$ & $1.73(0.26)$ \\
\hline TCT $(n=14)$ & $2.05(0.46)$ & $1.74(0.64)$ & $1.60(0.55)$ & $1.51(0.65)$ \\
\hline \multicolumn{5}{|c|}{ BTS- $Q-$ negative cognitions } \\
\hline $\operatorname{EXP}(n=12)$ & $43.25(15.32)$ & $33.69(18.23)$ & $33.67(18.78)$ & $31.41(16.94)$ \\
\hline TCT $(n=14)$ & $55.48(13.54)$ & $36.95(20.35)$ & $32.30(19.19)$ & $26.67(17.78)$ \\
\hline \multicolumn{5}{|l|}{$C C M s$} \\
\hline $\operatorname{EXP}(n=12)$ & 73.77 (8.99) & $48.46(20.39)$ & $38.83(25.79)$ & $48.00(28.56)$ \\
\hline TCT $(n=14)$ & $73.61(16.11)$ & $49.09(28.05)$ & $39.21(24.82)$ & 36.15 (24.99) \\
\hline
\end{tabular}


Table 4

Effects of EXP versus TCT on three physiological measures, self-reports of blushing, and self-reports of anxiety during conversation, and presentation (mean and S.D.)

\begin{tabular}{|c|c|c|c|}
\hline Variables & & Pretest & Posttest \\
\hline \multicolumn{4}{|l|}{ Conversation } \\
\hline \multirow[t]{2}{*}{ Cheek coloration $(\mathrm{V})$} & $\operatorname{EXP}(n=8)$ & $2.70(1.45)$ & $1.32(3.46)$ \\
\hline & $\mathrm{TCT}(n=11)$ & $2.74(1.56)$ & $2.52(1.40)$ \\
\hline \multirow[t]{2}{*}{ Cheek temperature $\left({ }^{\circ} \mathrm{C}\right)$} & $\operatorname{EXP}(n=9)$ & $3.17(0.13)$ & $3.15(0.15)$ \\
\hline & $\mathrm{TCT}(n=11)$ & $3.15(0.16)$ & $3.17(0.18)$ \\
\hline \multirow[t]{2}{*}{$\mathrm{SCL}^{\mathrm{a}}(\mu \mathrm{mho})$} & $\operatorname{EXP}(n=10)$ & $1.60(0.40)$ & $1.61(0.62)$ \\
\hline & $\mathrm{TCT}(n=10)$ & $1.53(0.72)$ & $1.39(0.66)$ \\
\hline \multirow[t]{2}{*}{ Self-reported blushing (transformed) ${ }^{\mathrm{b}}$} & $\operatorname{EXP}(n=12)$ & $-0.61(1.46)$ & $-1.28(1.61)$ \\
\hline & $\operatorname{TCT}(n=12)$ & $-1.08(2.01)$ & $-2.07(1.65)$ \\
\hline \multirow[t]{2}{*}{ Self-reported anxiety (transformed) ${ }^{b}$} & $\operatorname{EXP}(n=12)$ & $-0.68(1.86)$ & $-0.85(1.74)$ \\
\hline & $\mathrm{TCT}(n=12)$ & $-0.44(1.59)$ & $-1.97(1.63)$ \\
\hline \multicolumn{4}{|l|}{ Presentation } \\
\hline \multirow[t]{2}{*}{ Cheek coloration $(\mathrm{V})$} & $\operatorname{EXP}(n=8)$ & $2.87(2.26)$ & $1.98(0.63)$ \\
\hline & $\mathrm{TCT}(n=11)$ & $2.34(1.80)$ & $2.10(1.56)$ \\
\hline \multirow[t]{2}{*}{ Cheek temperature $\left({ }^{\circ} \mathrm{C}\right)$} & $\operatorname{EXP}(n=9)$ & $3.19(0.13)$ & $3.18(0.14)$ \\
\hline & TCT $(n=11)$ & $3.22(0.20)$ & $3.21(0.18)$ \\
\hline \multirow[t]{2}{*}{$\mathrm{SCL}^{\mathrm{a}}(\mu \mathrm{mho})$} & $\operatorname{EXP}(n=10)$ & $1.50(0.51)$ & $1.35(0.68)$ \\
\hline & $\mathrm{TCT}(n=10)$ & $1.52(0.57)$ & $1.32(0.62)$ \\
\hline \multirow[t]{2}{*}{ Self-reported blushing (transformed) ${ }^{\mathrm{b}}$} & $\operatorname{EXP}(n=12)$ & $-0.96(1.50)$ & $-0.93(1.33)$ \\
\hline & $\mathrm{TCT}(n=12)$ & $-0.69(1.88)$ & $-1.60(2.04)$ \\
\hline \multirow[t]{2}{*}{ Self-reported anxiety (transformed) ${ }^{\mathrm{b}}$} & $\operatorname{EXP}(n=12)$ & $-0.28(1.64)$ & $-0.55(1.70)$ \\
\hline & $\mathrm{TCT}(n=12)$ & $0.20(1.14)$ & $-0.36(1.26)$ \\
\hline
\end{tabular}

${ }^{a}$ SCL values are SQRT transformed.

b Self-reports are transformed using this formula: nvar $=\ln ((\operatorname{var}+1) /(101-$ var $))$.

FU II indicates that treated patients in both conditions improved further $[F \operatorname{hot}(2,19)=6.8, P<.01]$ (see also Table 3 ).

\subsection{3. (2a) Effects on cognitions}

A MANOVA yielded no significant difference with regard to cognitive change between the two treatments at posttest $[F \operatorname{hot}(2,23)=1.9, P>.1]$. However, at FU $\mathrm{I}$, there was a significant difference in favor of TCT [ $F$ hot $(2,23)=4.2, P<.05]$. This effect was mainly due to the variable 'BTS-Q negative cognitions' $[F(1,24)=5.0, P<.05]$, compared to the variable 'CCMs' $[F(1,24)=.07$, n.s. $]$.

Table 5

Percentage of patients showing clinically significant change and effect sizes of both treatment conditions at posttest, FU I, and FU II

\begin{tabular}{llllllll}
\hline & \multicolumn{2}{l}{ Percentage of clinically significant change (\%) } & & \multicolumn{3}{l}{ Effect size } \\
\cline { 2 - 4 } \cline { 6 - 8 } Fear of blushing & Posttest & FU I & FU II & & Posttest & FU I & FU II \\
\hline TCT & 43 & 50 & 58 & 1.14 & 1.40 & 1.48 \\
EXP & 42 & 75 & 89 & & 0.51 & 1.19 & 1.20 \\
\hline
\end{tabular}


Table 6

Descriptive statistics on descriptive variables of questionnaires (mean and S.D.) of patients who completed treatment in the EXP vs. TCT condition

\begin{tabular}{|c|c|c|c|c|}
\hline Variable & Pretest & Posttest & FU I & $\mathrm{FU} \mathrm{II}{ }^{\mathrm{a}}$ \\
\hline \multicolumn{5}{|c|}{ SPAI-social phobia } \\
\hline $\operatorname{EXP}(n=12)$ & $76.49(25.30)$ & $70.27(28.15)$ & $65.36(27.72)$ & $66.36(23.45)$ \\
\hline TCT $(n=14)$ & $92.00(24.61)$ & $83.10(30.61)$ & $75.25(27.08)$ & $70.76(30.33)$ \\
\hline \multicolumn{5}{|l|}{ SFA-arousal } \\
\hline $\operatorname{EXP}(n=12)$ & $7.58(5.99)$ & $4.58(4.68)$ & $6.42(5.09)$ & $3.56(3.40)$ \\
\hline $\mathrm{TCT}(n=14)$ & $8.71(4.89)$ & $8.21(6.64)$ & $7.07(5.92)$ & $3.75(3.08)$ \\
\hline \multicolumn{5}{|c|}{ SFA-performance } \\
\hline $\operatorname{EXP}(n=12)$ & $8.92(4.60)$ & $6.75(5.10)$ & $7.50(4.95)$ & $8.56(6.04)$ \\
\hline TCT $(n=14)$ & $9.64(4.45)$ & $8.71(5.47)$ & $9.21(4.49)$ & $6.75(5.05)$ \\
\hline \multicolumn{5}{|c|}{ Diary - composite fear and avoidance ${ }^{\mathrm{b}}$} \\
\hline $\operatorname{EXP}(n=11)$ & $0.53(0.38)$ & $0.36(0.26)$ & No follow-up & No follow-up \\
\hline TCT $(n=14)$ & $0.75(0.35)$ & $0.44(0.27)$ & & \\
\hline \multicolumn{5}{|c|}{$B T S-Q-$ positive cognitions } \\
\hline $\operatorname{EXP}(n=12)$ & $34.25(14.55)$ & $34.42(14.03)$ & $35.58(20.41)$ & $44.83(21.72)$ \\
\hline $\operatorname{TCT}(n=14)$ & $27.21(18.54)$ & $44.29(17.92)$ & $47.86(20.87)$ & $57.08(26.12)$ \\
\hline \multicolumn{5}{|c|}{ BTS-Q - blushing frequency past week } \\
\hline $\operatorname{EXP}(n=12)$ & $11.33(15.59)$ & $5.17(5.11)$ & $2.42(2.39)$ & $3.33(4.50)$ \\
\hline TCT $(n=14)$ & $11.92(8.69)$ & $4.00(2.99)$ & $4.29(7.57)$ & $3.92(5.12)$ \\
\hline
\end{tabular}

At FU II, this differential effect was gone $[F \operatorname{hot}(2,18)=1.8, P>.1]$. A comparison between posttest and FU II yielded a tendency for an overall further improvement $[F \operatorname{hot}(2,19)=3.2, P=.06]$ (see also Table 3 ).

\subsection{4. (2b) Effects on actual blushing}

Plethysmograph values at different occasions are summarized in Table 4. The MANOVA revealed no difference between TCT and EXP $[F \operatorname{hot}(2,17)=0.6] .^{3}$

\subsection{5. (2b) Effects on self-reported blushing and anxiety}

In Table 4, self-reported blushing and anxiety on different occasions are presented. The MANOVA revealed no significant difference between TCT and EXP on self-reported blushing $[F \operatorname{hot}(2,21)=1.8]$, nor on anxiety $[F \operatorname{hot}(2,21)=2.1, P>.1]$.

${ }^{3}$ The MANOVAs with regard to cheek temperature and skin conductance level revealed no significant main effect of group $[F \operatorname{hot}(2,18)=0.17$, and $F$ hot $(2,17)=0.24$, respectively]. The values at different occasions are summarized in Table 4. 


\subsubsection{Clinically significant change and effect sizes}

The percentages of patients who demonstrated clinically significant change on the BTS-Q 'fear of blushing' in both treatments are depicted in Table 5. No differences were found between the two treatments on posttest $\left[\chi^{2}(1)=0.1\right]$, FU I $\left[\chi^{2}(1)=1.7, P>.1\right]$, and FU II $\left[\chi^{2}(1)=2.4, P>.1\right]$. Effect sizes, however, were large at all occasions only for TCT.

For descriptive and informative purposes only, we also included the data from the other questionnaires that were filled out by patients (see Table 6). Interestingly, the BTS-Q self-reported blushing frequency decreases substantially in both groups over time.

\section{Discussion}

The main purposes of the present study were to examine the relative efficacy of behavioral treatment for fear of blushing above waiting list, and to examine potential differential treatment effects of EXP and TCT, on fear of blushing, cognitive change, actual blushing, and self-reported blushing and anxiety. The major results can be summarized as follows: (1) There was a significant effect of treatment above waiting with respect to fear of blushing, whereas patients in the waiting list and treatment condition made equal cognitive improvement; (2) TCT tended to produce better results with respect to fear of blushing than EXP at posttest, and at 6-weeks follow-up, TCT produced significantly better cognitive change than EXP; (3) At 1-year follow-up, treatment effects continued, whereas differential effects had disappeared; (4) The reduction in fear of blushing was not paralleled by a reduction in actual blushing during the behavioral assessments.

\subsection{Treatment success}

Compared to waiting, treatment was significantly more successful in reducing the blushing phobics' complaints. Thus, despite the short duration of the treatment, apparent improvements with regard to fear of blushing could be demonstrated. Besides, note that our patients' severity of complaints measured up with that of clinical subjects (see Bögels \& Reith, 1999). Patients with complaints of this severity usually receive longer treatment than the six sessions, provided in the present study. Note also that the patients who were assigned to the waiting-list group seemed to improve somewhat as well, which may have reduced the sensitivity to detect treatment effects in the present study. This improvement in the waiting-list group may well be due to waiting-list patients' optimism with regard to the forthcoming training. Also, the detailed intake, the keeping of a diary, the completion of questionnaires, and the behavioral tests, may have served as exposure assignments and as an attention placebo on the one hand, and have caused patients to put into perspective the severity of their complaints, on the other. Taken together, we feel that the significant improvements are promising. 


\subsection{TCT versus EXP}

At posttest, TCT tended to produce more favorable results with regard to fear of blushing. The larger effect sizes of TCT in contrast to EXP support this finding. At FU I, however, differential effects at this variable have disappeared. This indicates that TCT might act somewhat faster in dispelling fear of blushing in the short term, but that these initial differences converge in the end. In contrast, the percentage of clinically significant change is somewhat smaller for TCT than for EXP. Yet, since patients in the EXP condition started treatment with smaller pretest scores, it was easier for them to reach the point that was set for clinically significant change.

At FU I, cognitive change appeared to be significantly greater for TCT. Note also the descriptive results, suggesting that the credibility of BTS-Q positive cognitions had increased, especially for TCT. This implies that TCT is somewhat better in stimulating cognitive change than EXP. By giving patients the opportunity to experience disconfirming information, through becoming aware of their objective environment, TCT seems to promote cognitive change. Also, TCT inhibits patients to rely on their internal sensations rather than on external information to evaluate how they come across (Clark \& Wells, 1995). The finding that cognitive change during TCT takes place, independent of specific cognitive restructuring, has an important practical implication; that is, TCT is a treatment technique that can be acquired by therapists relatively easily, compared to cognitive therapy (Bögels et al., 1997), which might lead TCT to become the treatment of choice.

The absence of firm differential effects with respect to fear of blushing might be due to the fact that both treatment methods bear resemblances to each other. That is, both treatments imply the use of a hierarchy to practice difficult situations, and prescribe in-session and between-session exercises in which exposure to feared situations takes place. Because the EXP was maximalized regarding the dropping of safety behaviors (Wells et al., 1995), and TCT was set up to focus attention outward, it might be that patients in both groups were able to pick up disconfirming information with regard to their dysfunctional schemas about blushing. Furthermore, inspection of the descriptive data on SFA, directed at arousal, seems to indicate that this type of attention decreases in both treatments. Nevertheless, TCT's tendency to produce better results regarding fear of blushing is, given the small patient numbers in this study, worth mentioning. Yet, studies with greater patient numbers are needed to draw firmer conclusions concerning the relative efficacy of TCT.

\subsection{Changes in actual blushing}

Treatment did not affect actual blushing during the behavioral tests, neither as measured physiologically nor as indexed by self-reports. Several explanations could account for this result. Firstly, the absence of differences between treated 
and nontreated individuals with respect to actual blushing leads us to question the physiological response pattern of normal control subjects. It would be interesting to establish whether the physiological responses of nonfearful controls differ from the physiological responses of patients with fear of blushing. If not, there would be not much room for improvement with respect to the patients' blush responses, after all. Secondly, the two behavioral tests might have been too distinct from situations in patients' daily life, making changes in actual blushing as a result of treatment hard to detect. Thirdly, the absence of differences in actual blushing between treated patients and waiting-list controls might be due to the relatively short length of the treatments.

No differential treatment effects in actual blushing could be detected at posttest. However, since no treatment effects were demonstrated with respect to actual blushing, at all, it is questionable whether differential effects for type of treatment could be investigated. Yet, it seems that fear of blushing could be satisfactorily reduced, independent of a reduction in actual blushing. Moreover, the significant overall decrease of self-reported blushing at the second behavioral test (for waiting list and treatment at once), and the substantial decrease in the BTS-Q 'blushing frequency' subscale in both treated groups at posttest, further supports the notion that actual blushing and subjective blushing are not necessarily paralleled. Thus, fear of blushing seems to reflect a fearful preoccupation, irrespective of actual facial coloration.

In sum, TCT seems to be an equivalent and potentially more ameliorative alternative to EXP as a treatment for fear of blushing. The present study shows some evidence suggesting that TCT has more favorable effects. It remains to be investigated whether TCT is an effective treatment for social phobics with other somatic fears (like trembling and sweating), and for social phobics with nonsomatic fears.

\section{Acknowledgments}

The authors are grateful to Iris Engelhard, Annie Raven, and Annebeth Theunissen for their helpful assistance with the data acquisition and to Helene Andrea, Stefanie Duijvis, Meike Tiesema, Ingrid Vorage, and Saskia Weiberg who conducted the treatments. We also wish to thank Agnes Scholing for her helpful advice, and Erik Schouten and Herbert Hoijtink for their statistical assistance.

\section{References}

American Psychiatric Association. (1994). Diagnostic and statistical manual of mental disorders (4th ed.). Washington, DC: American Psychiatric Association.

Bögels, S. M. (1994). Cognitive therapy versus applied social skills training for fear of blushing, trembling and sweating. Paper presented at the 24th congress of the European Association of Behavioural and Cognitive Therapies, September 6-10, Corfu, Greece. 
Bögels, S. M., Alberts, M., \& de Jong, P. J. (1996). Self-consciousness, self-focused attention, blushing propensity and fear of blushing. Personality and Individual Differences, 21, 573-581.

Bögels, S. M., Mulkens, S., \& de Jong, P. J. (1997). Task concentration training and fear of blushing. Clinical Psychology and Psychotherapy, 4, 251-258.

Bögels, S. M., \& Reith, W. (1999). Validity of two questionnaires to assess social fears: the Dutch Social Phobia and Anxiety Inventory and the Fear of Blushing, Trembling, and Sweating-Questionnaire. Journal of Psychopathology and Behavioural Assessment, 21, 51-66.

Butler, G., Cullington, A., Munby, M., Amies, P., \& Gelder, M. (1984). Exposure and anxiety management in the treatment of social phobia. Journal of Consulting and Clinical Psychology, $52,642-650$.

Clark, D. M., \& Wells, A. (1995). A cognitive model of social phobia. In: R. G. Heimberg, M. R. Hope, D. A. Hope, \& F. R. Schneier (Eds.), Social phobia: diagnosis, assessment, and treatment (pp. 69-93). New York: Guilford Press.

Cohen, J. (1988). Statistical power analysis for the behavioral sciences. New York: Academic Press.

Daly, J. A., Vangelisti, A. L., \& Lawrence, S. G. (1989). Self-focused attention and public speaking anxiety. Personality and Individual Differences, 10, 903-913.

Edelmann, R. J. (1990). Coping with blushing. London: Sheldon Press.

Emmelkamp, P. M., Mersch, P. P., Vissia, E., \& van der Helm, M. (1985). Social phobia: a comparative evaluation of cognitive and behavioral interventions. Behaviour Research and Therapy, 23, $365-369$.

Feske, U., \& Chambless, D. L. (1995). Cognitive behavioral versus exposure only treatment for social phobia: a meta-analysis. Behavior Therapy, 26, 695-720.

Gelernter, C. S., Uhde, T. W., Cimbolic, P., Arnkoff, D. B., Vittone, B. J., Tancer, M. E., \& Bartko, J. J. (1991). Cognitive-behavioral and pharmacological treatments of social phobia: a controlled study. Archives of General Psychiatry, 48, 938-945.

Heimberg, R. G., Dodge, C. S., Hope, D. A., Kennedy, C. R., Zollo, L. J., \& Becker, R. E. (1990). Cognitive behavioral group treatment for social phobia: comparison with a credible placebo control. Cognitive Therapy and Research, 14, 1-23.

Hope, D. A., Gansler, D. A., \& Heimberg, R. G. (1989). Attentional focus and causal attributions in social phobia: implications from social psychology. Clinical Psychology Review, 9, 49-60.

Hope, D. A., Heimberg, R. G., \& Bruch, M. A. (1995). Dismantling cognitive-behavioral group therapy for social phobia. Behaviour Research and Therapy, 33, 637-650.

Jacobson, N. S., \& Truax, P. (1991). Clinical significance: a statistical approach to defining meaningful change in psychotherapy research. Journal of Consulting and Clinical Psychology, 59, 12-19.

Leary, M. R., Britt, T. W., Cutlip, W. D., \& Templeton, J. L. (1992). Social blushing. Psychological Bulletin, 112, 446-460.

Leary, M. R., \& Meadows, S. (1991). Predictors, elicitors, and concomitants of social blushing. Journal of Personality and Social Psychology, 60, 254-262.

Mattick, R. P., \& Peters, L. (1988). Treatment of severe social phobia: effects of guided exposure with and without cognitive restructuring. Journal of Consulting and Clinical Psychology, 56, $251-260$.

Mattick, R. P., Peters, L., \& Clarke, J. C. (1989). Exposure and cognitive restructuring for social phobia: a controlled study. Behavior Therapy, 20, 3-23.

Mulkens, S., Bögels, S. M., \& de Jong, P. J. (1999). Attentional focus and fear of blushing. Behavioural and Cognitive Psychotherapy, 27, 153-164.

Mulkens, S., de Jong, P. J., \& Bögels, S. M. (1997). High blushing propensity: fearful preoccupation or facial coloration? Personality and Individual Differences, 22, 817-824.

Mulkens, S., de Jong, P. J., Dobbelaar, A., \& Bögels, S. M. (1999). Fear of blushing: fearful preoccupation irrespective of facial coloration. Behaviour Research and Therapy, 37, 1119-1128.

Öst, L. G., Jerremalm, A., \& Johansson, J. (1981). Individual response patterns and the effects of different behavioral methods in the treatment of social phobia. Behaviour Research and Therapy, $19,1-16$. 
Scholing, A., Bögels, S. M., \& Velzen, C. van (1995). The Dutch Social Phobia and Anxiety Inventory (SPAI). Authorized translation.

Scholing, A., \& Emmelkamp, P. M. (1993a). Cognitive and behavioural treatments of fear of blushing, sweating or trembling. Behaviour Research and Therapy, 31, 155-170.

Scholing, A., \& Emmelkamp, P. M. (1993b). Exposure with and without cognitive therapy for generalized social phobia: effects of individual and group treatment. Behaviour Research and Therapy, 31, 667-681.

Spitzer, R. L., \& Williams, J. B. W. (1986). Structured clinical interview for DSM-III-R (SCID). New York: New York State Psychiatric Institute, Biometrics Research.

Taylor, S. (1996). Meta-analysis of cognitive-behavioral treatment for social phobia. Journal of Behavior Therapy and Experimental Psychiatry, 27, 1-9.

Turner, S. M., Beidel, D. C., Dancu, C. V., \& Stanley, M. A. (1989). An empirically derived inventory to measure social fears and anxiety: the Social Phobia and Anxiety Inventory. Psychological Assessment: A Journal of Consulting and Clinical Psychology, 1, 35-40.

Wegner, D. M., \& Giuliano, T. (1980). Arousal-induced attention to self. Journal of Personality and Social Psychology, 38, 719-726.

Wells, A., Clark, D. M., Salkovskis, P., Ludgate, J., Hackmann, A., \& Gelder, M. (1995). Social phobia: the role of in-situation safety behaviors in maintaining anxiety and negative beliefs. Behavior Therapy, 26, 153-161.

Wells, A., \& Matthews, G. (1994). Attention and emotion: a clinical perspective. Hove: Lawrence Erlbaum Associates. 